\title{
The Common Carotid Artery Thrombus and Embolic Stroke in the Setting of COVID-19 Infection
}

Sophia Angelides, Amit Chaudhari, Wengui Yu* Department of Neurology, University of California Irvine, CA, USA

*Corresponding Author: Wengui Yu, MD, PhD Department of Neurology, University of California, Irvine 200 S. Manchester Ave., 206E, Orange, CA 92868.

Received date: May 25, 2021; Accepted date: June 01, 2021; Published date: June 07, 2021

Citation: Sophia Angelides, Amit Chaudhari, Wengui Yu (2021) The Common Carotid Artery Thrombus and Embolic Stroke in the Setting of COVID-19 Infection. J. Neuroscience and Neurological Surgery. 9(2); DOI:10.31579/2578-8868/190

Copyright: (c) 2021 Wengui Yu, This is an open-access article distributed under the terms of The Creative Commons Attribution License, which permits unrestricted use, distribution, and reproduction in any medium, provided the original author and source are credited

\section{Abstract:}

Since the outbreak of the COVID-19 in Wuhan, China in 2019, there have been increasing reports of large vessel thrombosis and associated embolic stroke in patients with COVID-19 infection. The pathogenesis is thought to be multifactorial, including angiotensin-converting enzyme 2 receptor-mediated endothelial damage, rupture of atherosclerotic plaques, cytokine-storm induced-inflammation, and hypercoagulability. Here, we present a case of an otherwise-healthy COVID 19 patient who developed a right common carotid artery thrombus and embolic stroke with left sided numbness and weakness. Blood tests were significant for elevated levels of inflammatory biomarkers and di-dimer. Vessel imaging showed no evidence of underlying atherosclerosis or arterial dissection. Cardiac workup was unremarkable. The etiology of the carotid artery thrombus was likely COVID-19 related inflammation and hypercoagulability. He was started on apixaban $5 \mathrm{mg}$ twice daily for secondary stroke prevention. After 3 months, he was transitioned from apixaban to aspirin $81 \mathrm{mg}$ daily. At 4-month follow-up, he improved with only residual left arm numbness. Our case study suggests that in patients with large vessel thrombosis in the setting of Covid-19 infection, oral anticoagulation for 3 months followed by daily aspirin may be a reasonable treatment option for secondary stroke prevention.

Keywords: anticoagulation; COVID-19; carotid thrombus; hypercoagulability; stroke

\section{Introduction}

Coronavirus Disease 2019 (COVID-19) was first reported in Wuhan, China in 2019. [1] It is a viral illness that may manifest with symptoms involving multiple organs including the lungs, gastrointestinal tract, and central nervous system. [1,2] There have been numerous case reports of acute ischemic stroke from carotid artery thrombosis in patients with COVID-19 infection. [3-7] Large vessel thrombosis and embolic stroke were also reported in patients with COVID-19 infection and mild respiratory symptoms. [8] There appears to be a propensity towards the involvement of otherwise healthy large vessels. The pathogenesis of COVID-19 associated large vessel thrombosis is unclear, but emerging evidence suggest that angiotensin-converting enzyme 2 receptormediated endothelial damage, rupture of atherosclerotic plaques, cytokine-storm induced-inflammation, or hypercoagulability may be the possible mechanisms. [9-10] Here, we present a case of common carotid artery thrombus and embolic stroke in an otherwise healthy COVID-19 patient without significant stroke risk factors.

\section{Case Report}

The patient is a 58-year-old male with no significant past medical history. He initially presented with headaches, cough, fever, and general malaise. Chest x-ray showed bilateral patchy infiltrates. Real-time reverse transcription polymerase chain reaction (RT-PCR) was positive for coronavirus 2 RNA. Blood tests showed elevated $\mathrm{C}$ reactive protein (7.35$18.97 \mathrm{mg} / \mathrm{dL}$, reference range $0.00-1.00 \mathrm{mg} / \mathrm{dL})$, ferritin $(602-1334$ $\mathrm{ng} / \mathrm{ml}$, reference range $23-233 \mathrm{ng} / \mathrm{ml})$, lactate dehydrogenase $(316 \mathrm{U} / \mathrm{L}$, reference range 140-271 U/L), and d-dimer (590 ng/ml, reference range $<500 \mathrm{mg} / \mathrm{ml}$ ). He was treated with acetaminophen, dexamethasone, remdesivir, and supplemental oxygen via nasal cannula per current guideline. [11] He was also started on prophylactic doses of enoxaparin to prevent deep venous thrombosis. [11] On day 10 of hospitalization, the patient woke up with acute onset of left sided numbness and weakness. Initial National Institutes of Health Stroke Scale (NIHSS) score was 2. Neurological examination showed left arm pronator drift and decreased sensation in the left upper and lower extremities. He denied recent trauma or chiropractic neck manipulation. He also denied history of hypertension, 
diabetes, hyperlipidemia, smoking, or drug abuse. A computed tomography (CT) of the head did not show any hemorrhage or early ischemic signs. Given that the last-known-well time was at least five hours prior, and his neurologic deficits were mild, he was not indicated for acute stroke therapy with intravenous tissue plasminogen activator (tPA). Stat Magnetic Resonance Imaging (MRI) of the brain showed scattered acute infarcts in the right centrum semiovale and right posterior parietal/occipital lobe (Figure, A). Stroke workup showed total cholesterol $130 \mathrm{mg} / \mathrm{dL}$ (reference range $<200 \mathrm{mg} / \mathrm{dL}$ ), high-density lipoprotein $26 \mathrm{mg} / \mathrm{dL}$ (reference range >40 mg/dL), low-density lipoprotein $84 \mathrm{mg} / \mathrm{dl}$ (reference range $<160 \mathrm{mg} / \mathrm{dL}$ ), glycosylated hemoglobin $6.4 \% \%$ (reference range: $4.6-5.6 \%$; increased risk for diabetes: $5.7-6.4 \%$ ). Electrocardiogram and telemetry showed normal sinus rhythm. A transesophageal echocardiogram showed a left ventricular ejection fraction of $61 \%$ without wall motion abnormality, apical thrombus, or patent foramen ovale.
Approximately 8 hours after the symptom onset, his left arm muscle strength deteriorated to $3 / 5$ with decreased sensation in his left face, arm, and leg. A repeat MRI of the brain showed interval worsening of the infarctions in the right posterior parietal/occipital lobes (Figure, B). A CT Angiography of the head and neck revealed an intraluminal eccentric filling defect in the right common carotid artery consistent with an acute thrombus (Figure, $\mathbf{C} \boldsymbol{\&} \mathbf{D}$ ). There was no underlying arterial dissection or atherosclerotic disease. Given that there was no large vessel occlusion, and that his neurological deficits were very mild, neither endovascular thrombectomy nor carotid endarterectomy was indicated. The patient was started on therapeutic doses of anticoagulation with apixaban $5 \mathrm{mg}$ twice a day for secondary stroke prevention ${ }^{3}$ and atorvastatin $20 \mathrm{mg}$ daily for mild dyslipidemia with goal of low-density lipoprotein $<70 .{ }^{12} \mathrm{He}$ received physical and occupational therapy and improved significantly with only mild left arm pronator drift and paresthesia in his left face and arm at hospital discharge.

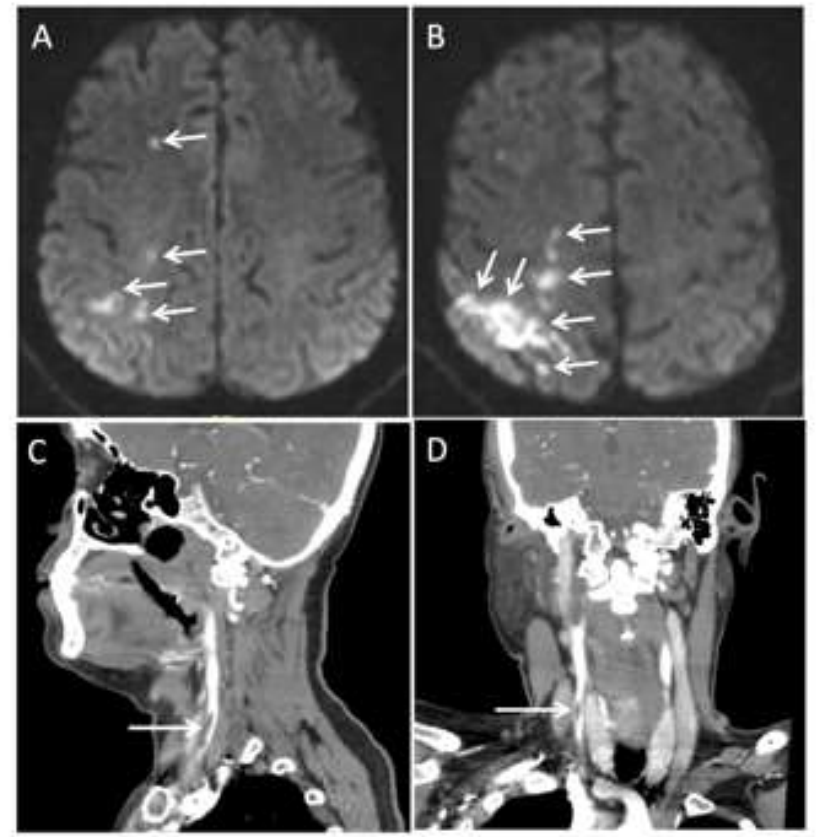

Figure 1. Embolic stroke from common carotid artery thrombus. MRI of the brain showed evolving acute embolic infarcts in the right frontal and parietal lobes (arrows in A and B). CT angiogram demonstrated an intraluminal filling defect in the right common carotid artery (arrow in C and D), consistent with acute thrombus.

The patient had a clinic follow-up 2 weeks after his stroke. His left arm weakness resolved completely but he continued to have residual numbness of the left face and arm. After 3 months, he was transitioned from apixaban to aspirin $81 \mathrm{mg}$ daily. At 4-month follow-up, he only had residual left arm numbness. He had no recurrent stroke.

\section{Discussion}

The etiology of the common carotid artery thrombosis and associated embolic stroke in our otherwise healthy patient was likely COVID-19 related inflammation and hypercoagulable state. $[9,10]$

In a case series of 6 patients with COVID-19 related internal carotid artery thrombus and embolic stroke, all patients were found to have vascular risk factors and elevated inflammatory biomarkers. [6] COVID-19 related inflammation may result in the rupture of vulnerable atherosclerotic plaques, resulting in thrombosis and acute ischemic stroke in these patients. [2,6] However, a large meta-analysis of COVID-19 related ischemic stroke found that $46.5 \%$ patients had large vessel occlusion and only $7.39 \%$ patients were atherothrombotic in etiology. [10] Similar to our case, many patients appeared to have thrombi in otherwise healthy large vessels. [7-8]

Currently, there is no consensus on the management of COVID-19 related large vessel thrombosis and associated embolic stroke. There have been case reports of treatment with intravenous tPA, thrombectomy, or carotid endarterectomy followed by antiplatelet or anticoagulation theapy. [3-8] 
Large thrombus is often associated with higher risk of complete artery occlusion or distal embolization in the middle cerebral artery. A recent case report showed complete resolution of Covid-19 related large vessel thrombi in 5 patients with 10 days of anticoagulation therapy. [3] Our patient was not a candidate for intravenous tPA or thrombectomy. Hence, we started apixaban $5 \mathrm{mg}$ twice daily for secondary stroke prevention. Since the thrombosis was provoked by COVID-19 infection, anticoagulation for 3-months followed by aspirin appears to be reasonable treatment plan.

Of note, our case study has significant limitations. First, our findings lack scientific rigor and cannot be generalized to the COVID-19 related stroke population. Second, data interpretation might be biased. However, our case report may contribute useful information to better understanding and management of carotid artery thrombus and stroke in the setting of COVID-19 infection.

\section{Conclusion}

Our case study suggests that COVID-19 related inflammation and hypercoagulable state may cause common carotid artery thrombus and embolic stroke. Oral anticoagulation for 3-months followed by daily aspirin may be a reasonable treatment option for secondary stroke prevention.

\section{References}

1. Zhu N, Zhang D, Wang W, et al. A Novel Coronavirus from Patients with Pneumonia in China, 2019. N Engl J Med. 2020;382(8):727733. doi:10.1056/NEJMoa2001017

2. Ellul MA, Benjamin L, Singh B, Lant S, Michael BD, Easton A, et al. Neurological associations of COVID-19. Lancet Neurol. 2020 Sep;19(9):767-783.

3. Oxley TJ, Mocco J, Majidi S, et al. Large-vessel stroke as a presenting feature of Covid-19 in the young. $\mathrm{N}$ Engl J Med 2020;382:e60.

4. Wang A, Mandigo GK, Yim PD, et al. Stroke and mechanical thrombectomy in patients with COVID-19: technical observations and patient characteristics. J Neurointerv Surg 2020;12:648-653.

5. Viguier A, Delamarre L, Duplantier J, Olivot JM, Bonneville F. Acute ischemic stroke complicating common carotid artery thrombosis during a severe COVID-19 infection. J Neuroradiol. 2020;47(5):393-394. doi:10.1016/j.neurad.2020.04.003

6. Mohamud AY, Griffith B, Rehman M, Miller D, Chebl A, Patel SC, Howell B, Kole M, Marin H. Intraluminal Carotid Artery Thrombus in COVID-19: Another Danger of Cytokine Storm? AJNR Am J Neuroradiol. 2020 Sep;41(9):1677-1682. doi: 10.3174/ajnr.A6674.

7. Cancer-Perez S, Alfayate-García J, Vicente-Jiménez S, et al. Symptomatic Common Carotid Free-Floating Thrombus in a COVID-19 Patient, Case Report and Literature Review [published online ahead of print, 2021 Mar 6]. Ann Vasc Surg. 2021;S08905096(21)00194-1. doi:10.1016/j.avsg.2021.02.008

8. Fara MG, Stein LK, Skliut M, Morgello S, Fifi JT, Dhamoon MS. Macrothrombosis and stroke in patients with mild Covid-19 infection. $J$ Thromb Haemost. 2020;18(8):2031-2033. doi:10.1111/jth.14938

9. Lou M, Yuan D, Liao S, Tong L, Li J. Potential mechanisms of cerebrovascular diseases in COVID-19 patients. J Neurovirol. 2021 Feb 3;1-17.

10. Fraiman P, Godeiro Junior C, Moro E, Cavallieri F, Zedde M. COVID-19 and Cerebrovascular Diseases: A Systematic Review and Perspectives for Stroke Management. Front Neurol. 2020;11:574694. Published 2020 Nov 5. doi:10.3389/fneur.2020.574694

11. Wiersinga WJ, Rhodes A, Cheng AC, Peacock SJ, Prescott HC. Pathophysiology, Transmission, Diagnosis, and Treatment of Coronavirus Disease 2019 (COVID-19): A Review. JAMA. 2020 Aug 25;324(8):782-793. doi: 10.1001/jama.2020.12839. PMID: 32648899.

12. Kleindorfer DO, Towfighi A, Chaturvedi S, et al. 2021 Guideline for the Prevention of Stroke in Patients With Stroke and Transient Ischemic Attack: A Guideline From the American Heart Association/American Stroke Association [published online ahead of print, 2021 May 24]. Stroke. 2021;STR0000000000000375.

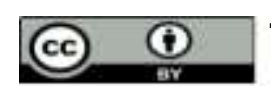

This work is licensed under Creative Commons Attribution 4.0 License
To Submit Your Article Click Here: Submit Manuscript

DOI:10.31579/2578-8868/190
Ready to submit your research? Choose Auctores and benefit from:

* fast, convenient online submission

* rigorous peer review by experienced research in your field

* rapid publication on acceptance

* authors retain copyrights

* unique DOI for all articles

* immediate, unrestricted online access

At Auctores, research is always in progress.

Learn more www.auctoresonline.org/journals/neuroscience-andneurological-surgery 